\title{
Florbela Espanca na pintura de Isabel Nunes
}

Florbela Espanca in painting by Isabel Nunes

\section{Elisangela da Rocha Steinmetz}

Universidade de Lisboa elisangela.steinmetz@edu.ulisboa.pt 
Iniciar o ano de 2021 escrevendo sobre um livro que trás à cena a obra de Florbela Espanca é pertinente, visto que, depois de um longo período de trabalho e negociações, foi divulgada, no final de dezembro de 2020, pelo investigador Tiago Salgueiro, a criação da Casa Museu Florbela Espanca ${ }^{49}$, em Vila Viçosa, no local em que a autora residiu durante a sua infância e adolescência. 0 espaço além de ser importante para a preservação da arte e da memória dessa admirável escritora pretende também possibilitar novos enfoques sobre Florbela. Novos enfoques, novos diálogos, razão pela qual, entre outras, a pintura de Isabel Nunes acerca dos sonetos de Florbela deve ser lembrada, pois revela esse alargamento de fronteiras com outras artes, como o cinema, o teatro, etc. e, no caso, com a pintura, que a obra da poeta instiga e inspira. Um livro irresistível é o que se pode dizer da obra Florbela Espanca na pintura de Isabel Nunes, publicada pela editora Caleidoscópio, lançada na Biblioteca Nacional de Portugal em 20 de novembro de 2018. Nele encontramos trinta e cinco poemas de Florbela Espanca revisitados pela ótica da artista Isabel Nunes, versos que ganham formas delicadas e sutis numa arrebentação de cores que se entrelaçam em diálogo com a escrita de Florbela. Assim, a leitura da obra permite uma experiência onde a emoção se intensifica na percepção do conjunto de códigos utilizados numa e noutra arte - escrita e pintura conduzem uma imersão no espelhamento das tintas; de canetas, lápis, pincéis e derramadas espátulas. Para além das obras de arte a edição traz alguns textos de destacadas figuras da crítica e da arte que com suas colaborações iluminam a cena onde a página florbeliana se encontra com a tela de Isabel Nunes.
0 primeiro desses textos pertence à própria pintora, "Entre tanto... Florbela" e é traçado em poucas linhas, nas quais ela se revela apaixonada pela poesia de Florbela, a qual pintou ao longo de doze anos, na intenção de um dia ver poesia e pintura reunidas num livro, revela Isabel Nunes, num gesto que homenageia tanto a poetisa quanto a mulher que ela foi. E faz um irrecusável convite: "Afastemos os estigmas, condenemos os preconceitos e reprovemos a segregação para nos debruçarmos através do meu olhar enquanto pintora numa das mais belas obras poéticas - Florbela Espanca." (p.7).

"As cores de Florbela", de Nuno Júdice, comenta aquilo que se pode ou não saber sobre o gosto de Florbela no que toca a pintura. Destaca, também, alguns nomes da literatura e da música que através de correspondências (e mesmo na obra) eram notadamente apreciados por ela, assim como o seu justificado apreço pela fotografia, pela relação do pai com esta arte; observando a maneira como a poetisa "se descreve a si própria de um modo quase fotográfico" (p.10). 0 poeta e crítico, entre outros aspectos, destaca a forma como a obra de Florbela convoca para a visualização das cenas e a presença do mundo da arte decorativa no contexto da sua escrita: "Se passarmos da poesia à prosa, e percorrermos os seus contos, esta percepção visual dos cenários, quer sejam interiores quer naturais, continua a ser uma dominante do seu estilo." (p.14) Além disso, aponta algumas cores que marcam presença na obra da poetisa: o roxo, o preto, 0 branco, o dourado e o vermelho; analisando as conotações que esses tons adquirem nos textos tanto em verso quanto em prosa. No texto de Júdice temos um breve panorama do

49 Mais informações podem ser obtidas em: https://www.casaflorbelaespanca.com/ 
contexto artístico que, tanto por gosto pessoal como por efeito de uma época, bem como, por escolha do modo de escrita, acabam por marcar a produção de Florbela, que Nuno Júdice designa como "pintora de palavras" (p.15).

Já em "A voz da Tília", Isabel Lousada apresenta o poema homónimo e recorda um cenário partilhado - redondezas que tanto ela quanto Florbela percorreram, uma rua em Quarteira no Algarve -; "privilegiando uma relação pessoal e subjetiva - para dizer um fio de relação possível entre mundos e sentidos." (p.19). E, seguindo por esse fio, com sensibilidade, Lousada aborda o poema e conecta-o com versos de outros autores que também se referem a essa flor, cuja voz e encanto encontram eco na seleção feita pela pesquisadora e ensaísta: Sophia de Mello Breyner Andersen, José Luís Peixoto, José Gomes Ferreira e Bernardette Capelo.

$\mathrm{Na}$ alquimia de vozes que realiza põe essas muitas "Tílias" em conversa e revela na flor cantada, entre outros aspectos, "consciência da passagem do tempo, a brevidade da vida, mas também a imersão do humano na natureza e na intemporalidade cósmica." (p.24), desvendando a dimensão simbólica da tília.

Em "Isabel \& Florbela diálogos poéticos", Fernando António Baptista Pereira trata da relação entre as imagens e as palavras, que conforme ele, em dado contexto, "parece saturada" e que, no entanto, encontra "empreendimentos como os de Isabel Nunes, revisitando com a sua delicada pintura, feita de subtis transparências e materialidades, poemas exaltantes de Florbela Espanca, (...) reafirmando que ainda é possível pôr a dialogar a Poesia e a Pintura" (p.28). Ademais, destaca as qualidades do trabalho da pintora, observando que "As obras fazem alternar motivos figurativos longinquamente inspirados pelo título e pela letra dos poemas e ostensivas rugosidades matéricas, muito próprias do trabalho da artista ao longo dos anos," (p. 29). Todos os textos que antecedem o capítulo "Florbela e Isabel" preparam o leitor para melhor usufruir daquilo que será um primoroso encontro entre literatura e pintura. Quando numa explosão de cores, onde em algumas telas ora prevalece 0 dourado e 0 vermelho e noutras o azul, o roxo e as matizes que seguem até ao negro, penetramos num mundo de sonho e imaginação, perpetuado por sentimentos de beleza, de paixão e, às vezes, as desolações com que se deparam. Página a página, nossos olhos, nossos corações, nossas almas podem fruir dum bailado entre a Castelã da Tristeza e a senhora de mágicos pincéis: Isabel Nunes.

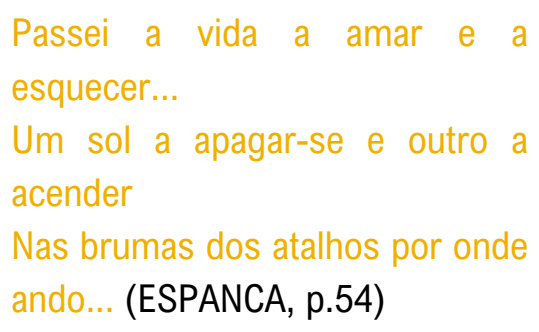

Mais uma vez Florbela ressurge vibrante a acender, dificilmente será esquecida aquela que como poeta é "mais alto", que soube "morder como quem beija!" e que, com o trabalho de Isabel Nunes, parece "condensar 0 mundo num só grito!". 


\section{Bibliografia}

ESPANCA, Florbela; NUNES, Isabel; LOUSADA, Isabel; JÚDICE, Nuno; PEREIRA, Fernando António Baptista. Florbela Espanca na pintura de Isabel Nunes. Portugal: editora Caleidoscópio, s/d.

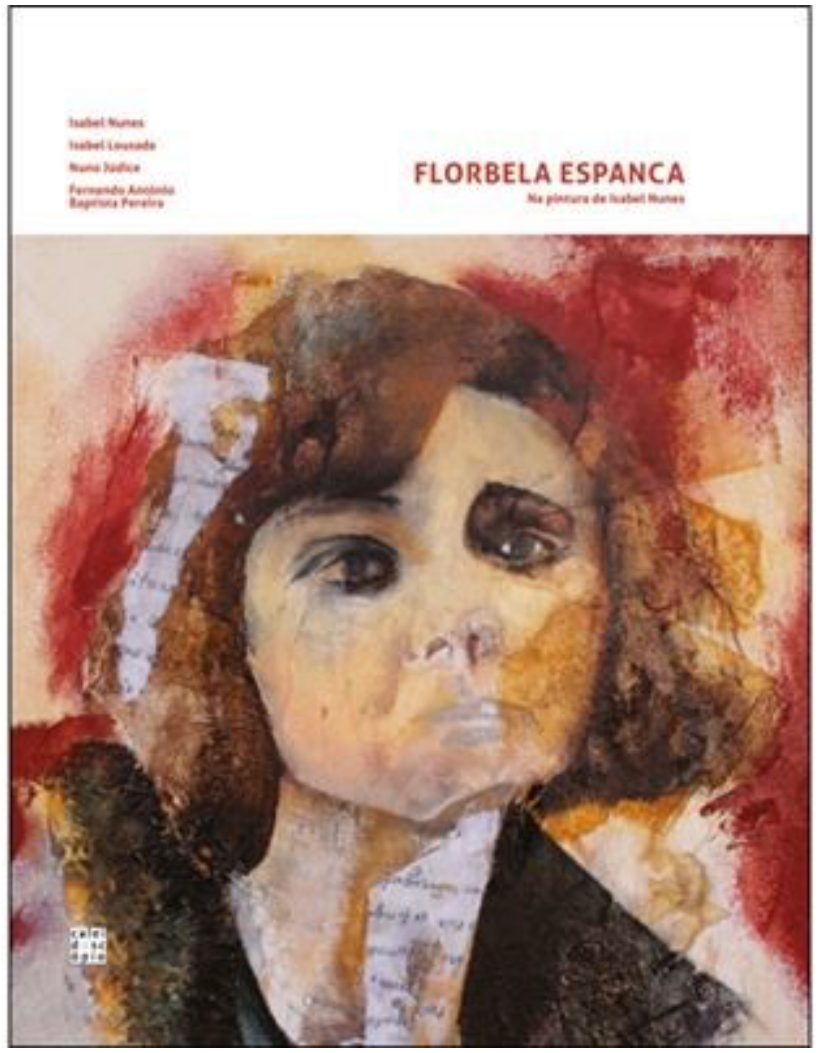

